Emslie, G. J. \& Mayes, T. L. (2001) Mood disorders in children and adolescents: psychopharmacological treatment. Biological Psychiatry, 49, 1082-1090.

Gross, C., Zhuang, X., Stark, K., et al (2002) Serotonin SA $_{1 \mathrm{~A}}$ receptor acts during development to establish normal anxietylike behaviour in the adult. Nature, 416, 396-400.

Heim, C. \& N emeroff, C. B. (2002) N eurobiology of early life stress: clinical studies. Seminars in Clinical Neuropsychiatry, 7, 147-159.

Jensen, P. S., H inshaw, S. P., Swanson, J. M., et al (2001) Findings from the $\mathrm{NIMH}$ Multimodal Treatment Study of ADHD (MTA): implications and applications for primary care providers. Journal of Developmental and Behavioral Pediatrics, 22, 60-73.

Kaufman, J., Plotsky, P. M., N emeroff, C. B., et al (2000) Effects of early adverse experiences on brain structure and function: clinical implications. Biological Psychiatry, 48, 778-790.

Laor, N., Wolmer, L., Mayes, L. C., et al (1997) Israeli preschool children under Scuds: a 30-month follow-up. Journal of the American Academy of Child and Adolescent Psychiatry, 36, 349-356.

Meaney, M. J. (2001) Maternal care, gene expression, and the transmission of individual differences in stress reactivity across generations. Annual Review of Neuroscience, 24, 1161-1192.
Pine, D. S. \& Cohen, J. A. (2002) Trauma in children and adolescents: risk and treatment of psychiatric sequelae. Biological Psychiatry, 51, 519-531.

Rauch, S. A., Hembree, E. A. \& Foa, E. B. (2001) Acute psychosocial preventive interventions for posttraumatic stress disorder. Advances in M ind-Body Medicine, 17, 187-191.

Research U nit on Pediatric Psychopharmacology Anxiety Study Group (2001) Fluvoxamine for the treatment of anxiety disorders in children and adolescents. New England Journal of M edicine, 344, 1279-1285.

Schlenger, W. E., Caddell, J. M., Ebert, L, et al (2002) Psychological reactions to terrorist attacks: findings from the $\mathrm{N}$ ational Study of Americans' Reactions to September 11. Journal of the American Medical Association, 288, 581-588.

Shaffer, D. \& C raft, L. (1999) Methods of adolescent suicide prevention. Journal of Clinical Psychiatry, 60 (suppl. 2), 70-74; discussion 75-76, 113-116.

Steinberg, L. \& Avenevoli, S. (2000) The role of context in the development of psychopathology: a conceptual framework and some speculative propositions. Child Development, 71, 66- 74.

Thabet, A. A., Abed, Y. \& Vostanis, P. (2002) Emotional problems in Palestinian children living in a war zone: a cross-sectional study. Lancet, 359, 1801-1804.

\title{
Impact of trauma on Palestinian children's mental health: lessons from the Gaza studies
}

\section{Panos Vostanis}

Professor of Child and Adolescent Psychiatry, University of Leicester, Westcotes House, Westcotes Drive, Leicester LE3 0QU, UK, email pv11@le.ac.uk

hildren exposed to violence are at high risk of developing a range of mental health problems, predominantly post-traumatic stress disorder (PTSD) and depression (Yule, 1999). Children in war zones can be affected not only directly but also indirectly, for example through their basic health needs not being met, the loss of family members, disruption of social networks, internal displacement and their parents' responses.

Since the late 1990s, we have run a number of studies in the Gaza Strip, with Dr Abdel Aziz Thabet and his research team. 0 ur initial study, after the end of the first intifada (uprising), established a high prevalence rate (41\%) of post-traumatic stress reactions among children (aged 611 years) and their significant association with traumatic events experienced by the children, as well as with other behavioural and emotional problems (Thabet \& Vostanis, 1999a). The trauma experienced included injuries, death or imprisonment of family, relatives or friends, as well as day and night raids.

When we re-interviewed these children $(n=234)$ 1 year later, well atter the 0 slo agreement and the renewal of the peace process in the region, the prevalence rate of post-traumatic stress reactions had decreased to $10 \%$ (Thabet \& Vostanis, 2000). The findings suggested that most reactions were acute and resolved in the absence of further conflict, but there were also a substantial number of children who suffered chronic and resistant posttraumatic reactions, which could benefit from specialist treatment.

Palestinian children's mental health problems were compounded by their extreme adverse socio-economic circumstances, which is a common finding in research with children who are victims of political conflict. Most traumatic events occur in refugee camps in the West Bank and the Gaza Strip, where generations of children have been born for 55 years with little hope of escape. There has been a continuous growth of the population, which has now reached a density of $2300 / \mathrm{km}^{2}$. Refugees make up $63 \%$ of the population, and $51 \%$ of refugees are under 15 years of age (Thabet \& Vostanis, 1999b).

The second intifada (Al Aqsa) started in September 2000. Although we could not access all areas of the $G$ aza Strip to follow up the previous sample, we repeated the epidemiological study with a new cohort, and found that the prevalence rates of post-traumatic stress reactions had again risen dramatically, as a consequence of high exposure to new traumatic events. Children's emotional presentations were strongly correlated with maternal psychopathology (i.e. mothers' response to trauma) (Thabet et al, 2001). Traumatic events had changed since the previous confilict, with most children reporting watching pictures of mutilated bodies on television, and witnessing the bombing of people and houses.
Palestinian children's mental health problems were compounded

by their extreme adverse socioeconomic circumstances, which is a common finding in research with children who are victims of political conflict. 
In order to understand the underlying mechanisms operating between trauma and mental health problems, in a subsequent study we compared children whose houses had been demolished with children matched for age and gender from areas indirectly exposed to other types of traumatic events, mainly through the media and adults (Thabet et al, 2002). Children directly exposed to war trauma reported significantly higher post-traumatic stress and fears. In contrast, children exposed to other types of traumatic events reported significantly more anticipatory anxiety and cognitive expressions of distress.

A number of factors thus appear to mediate exposure to trauma, such as:

o the duration and severity of the trauma

o the impact on adults through fear, anger or unemployment

o the children's own anger and internalisation of the conflict

O their developmental changes in relation to cognitive processing of the meaning of trauma.

A combination of these factors could lead to a state of learned helplessness and anger expressed in extreme forms. Such states are already proving difficult to resolve among the young adult generation, now even among young women, which was previously outside the cultural norms. Such coping strategies are not easy to modify by mere psycho logical means (Thabet et al, 2003).

Following the epidemiological research, we recently completed a controlled intervention trial of group debriefing (supportive psychotherapy) and school-based psychoeducation for traumatised children in refugee camps across the Gaza Strip, the data from which we are in the process of analysing and disseminating. A preliminary analysis suggests that, in the presence of ongoing conflict, neither intervention had a positive impact on children's symptoms, despite their satisfaction with the individual treatment. This by no means negates the importance of mental health services and psychiatrists in alleviating children's distress, but does indicate the limitations of making an impact on a larger scale in the absence of other measures to safeguard children's safety and basic needs (Southall \& Abbasi, 1998).

Although there is some research evidence on strategies to prevent or minimise children's response to trauma in such circumstances, these are more likely to be successful through agencies operating in the area in collaboration with schools, which are the main source of stability and safety for the children. International organisations such the $U$ nited $N$ ations (under whose auspices all schools in the refugee camps operate) and the U nited $\mathrm{N}$ ations Children's Fund (UN ICEF) have a major role to play in providing as much as is humanly possible in the way of socio-economic stability, education, alternative coping strategies and awareness of the impact of trauma in these sad and untoward circumstances.

The treatment of resulting psychiatric disorders, particularly post-traumatic stress and depression, needs to be viewed in the same framework, but also taking into account cultural issues and sparse specialist resources (Thabet et al, 2000). Children requiring interventions can be identified through schools and primary health clinics, such as those run by the World $\mathrm{H}$ ealth $\mathrm{O}$ rganization. The nature of intervention can be informed by clinical and research evidence from work with victims of community violence, abuse, natural disasters and political persecution. Group interventions are more cost-effective, and there is evidence for the effectiveness of co gnitive- behavioural (Smith et al, 1999) and psychodynamic therapy (Weine et $\mathrm{al}, 1998)$. These interventions need to take into account children's develo pmental needs and expression of psychopathology, and should not simply replicate treatment programmes originally developed for adults. They also need to take into account the diversity and comorbidity of child psychiatric disorders, instead of only targeting PTSD . In addition to assessment and treatment, child psychiatrists have an important role to play in setting-up training for nonspecialiststaff, to enable them to detect and manage simple cases and refer the more complex ones.

A political resolution is, of course, the only long-term option for these children, before future generations from both Palestine and Israel are condemned to more hatred, fanaticism and perpetuation of the meaningless cycle of violence.

\section{References}

Smith, P., Perrin, S. \& Yule, W. (1999) Cognitive behaviour therapy for post traumatic stress disorder. Child Psychology and Psychiatry Review, 4, 177-182.

Southall, D. \& Abbasi, K. (1998) Protecting children from armed conflict: the UN convention needs an enforcing arm. BMJ, 316, 1549-1550

Thabet, A. A. \& Vostanis, P. (1998) Social adversities and anxiety disorders in the Gaza Strip. Archives of Disease in Childhood, 78, 439-442.

Thabet, A. A. \& Vostanis, P. (1999a) Posttraumatic stress reactions in children of war. Journal of Child Psychology and Psychiatry, 40, 385-391.

Thabet, A. A. \& Vostanis, P. (1999b) Visit to the Gaza Community Mental Health Programme: training in child mental health. Psychiatric Bulletin, 23, 300-302.

Thabet, A. A. \& Vostanis, P. (2000) Post traumatic stress disorder reactions in children of war: a longitudinal study. Child Abuse and Neglect, 24, 291-298.

Thabet, A. A., Stretch, D. \& Vostanis, P. (2000) Child mental health problems in Arab children: application of the Strengths and Difficulties Q uestionnaire. International Journal of Social Psychiatry, 46, 266-280.

Thabet, A. A., Abed, Y. \& Vostanis, P. (2001) Effect of trauma on the mental health of Palestinian children and mothers in the Gaza Strip. Eastern Mediterranean $\mathrm{H}$ ealth Journal, 7, 1-9.

Thabet, A. A., Abed, Y. \& Vostanis, P. (2002) Emotional problems among Palestinian children living in a war zone. Lancet, 359, 1801- 1804.

Thabet, A. A., Tischler, V. \& Vostanis, P. (2003) Maltreatment and coping strategies among male adolescents living in the $\mathrm{G}$ aza Strip. Child Abuse and N eglect, in press.

Weine, S., Kulenovic, A. D., Pavkovic, I., et al (1998) Testimony psychotherapy in Bosnian refugees: a pilot study. American Journal of Psychiatry, 155, 1720-1727.

Yule, W. (1999) Post-traumatic stress disorder. Archive of Disease in Childhood, 80, 107-109. 